\title{
MONIZ, A. B. (2018). ROBÓTICA E TRABALHO. O FUTURO HOJE. LISBOA: GLACIAR
}

\section{Nuno Boavida}

Centro Interdisciplinar de Ciências Sociais (CICS.NOVA), Faculdade de Ciências Sociais e Humanas, Universidade NOVA de Lisboa, Avenida de Berna, 26C, 1069-061 Lisboa, Portugal. Email:

nuno.boavida@fcsh.unl.pt

O livro "Robótica e Trabalho. O Futuro Hoje" de António Brandão Moniz foi lançado em Março de 2018 e aborda a relação entre a robótica e o mundo trabalho num contexto nacional e internacional. O livro é fruto de um convite da Fundação Luso-Americana para o Desenvolvimento e pertence à coletânea intitulada "A Ciência Disruptiva" da editora Glaciar. O autor do livro é Professor Associado com agregação de Sociologia Industrial da Universidade Nova de Lisboa, investigador do Institute of Technology Assessment and System Analysis (ITAS) do Karlsruhe Institute of Technology (KIT) na Alemanha e coordenador da Agenda Nacional de Investigação e Inovação em "Trabalho, robotização e qualificação do emprego em Portugal" promovida pelo Ministério da Ciência e Tecnologia.

O livro pretende contribuir para o debate público atual sobre a relação entre tecnologia e trabalho, visível no número crescente de debates na televisão e de entrevistas em revistas e semanários nacionais e internacionais. Os desenvolvimentos tecnológicos recentes na área de automação, robótica e inteligência artificial têm motivado um maior debate mediático também em Portugal, embora os contributos científicos nacionais para a discussão sejam ainda relativamente limitados. O debate sobre tecnologia e trabalho já existe com manifesta importância na comunidade científica desde os anos de 1970, com publicações e debates organizados em torno da importância da introdução de sistemas automatizados (i.e., de controlo numérico e robotizados), do impacto na desqualificação da sociedade pós-industrial e da emergência dos sistemas flexíveis de produção que permitiam novas opções organizacionais. O livro enquadra a discussão atual num contexto histórico, onde nos anos 1970 e 1980 a principal questão era a de poderem ser apenas os postos de trabalho com conteúdos pobres (monotonia, repetibilidade, etc.) os mais facilmente automatizáveis. São centrais os fatores que podem motivar a perda de postos de trabalho que não estão diretamente relacionados com as políticas macroeconómicas, com os problemas dos mercados globais ou com as disfunções de gestão empresarial. O autor percorre os principais debates técnicos e sociológicos acerca da relação entre tecnologia e trabalho, e mais concretamente acerca da robótica, em torno de fatores como o emprego, desemprego, produtividade e vagas de automação industrial (e.g. Indústria 4.0). 
O livro inicia-se com um capítulo sobre a relação entre tecnologia e emprego abordando o contexto português. De seguida, o autor debruça-se sobre a automação como processo de racionalização, procedendo a uma reflexão teórica sobre automação, tendências, produtividade e emprego, incluindo na discussão temas como o determinismo tecnológico, opções organizacionais e os principais estudos de referência. O capítulo seguinte é sobre robótica como uma tecnologia de referência, apresentando uma discussão sobre a definição de robótica e a sua emergência como tecnologia avançada no desenvolvimento da automação, e finalizando com referências a aplicações da robótica na indústria, noutros setores de atividade económica e na vida privada, bem como em novos domínios e setores. Este capítulo inclui ainda um subcapítulo acerca da relação indivíduo-robô, onde se discutem as caraterísticas desta relação em ambiente de trabalho e ambientes complexos de trabalho, a intuitividade como objeto da relação da robótica com os humanos, e a possível contribuição da robótica para a melhoria das condições de trabalho. O quinto capítulo explica a emergência das questões éticas, legais e sociais (ELS) associadas aos desenvolvimentos tecnológicos. De seguida, o livro descreve o desenvolvimento da robótica em Portugal apresentando os pioneiros, os principais campos de investigação, as aplicações industriais e as tendências de desenvolvimento da robótica no país, incluindo a elaboração da já referida Agenda Nacional de Investigação e Inovação sobre "Trabalho, Robotização e Qualificação do Emprego em Portugal" para os desenvolvimentos da área no futuro. No sétimo e último capítulo, o autor apresenta as principais conclusões em relação aos limites da investigação em robótica, às potencialidades de desenvolvimento da robótica, à polémica acerca da substituição dos humanos pelos robôs nos postos de trabalho e às perspetivas de novas aplicações em Portugal.

O livro enquadra de uma forma genérica os processos de automação da produção industrial no contexto da sua evolução histórica, centrando-se mais significativamente nas últimas décadas. $\mathrm{O}$ autor introduz as principais obras de referência do pensamento sociológico desde a (primeira) revolução industrial, e inclui a descrição das principais inovações tecnológicas associadas a estas vagas de transformação na produção. Moniz argumenta que a automação, como fenómeno da racionalização do processo produtivo, tem sido realizada de modo contínuo e em paralelo com o desenvolvimento das economias e das sociedades, sem grandes surtos de desemprego. Assim o demonstra o citado estudo de Arntz, Gregory e Zierahn (2016) que permitiu relativizar o alarmismo existente entre muitos analistas em relação ao impacto da automatização no mercado de trabalho, ao combinar os indicadores subjetivos de automatização de 70 profissões do estudo de Frey e Osborne (2013) com os dados do PIAAC (Programme for the International Assessment 
of Adult Competencies). De facto, Arntz, Gregory e Zierahn concluíram que apenas 9\% de todos os indivíduos nos EUA enfrentam uma alta taxa de automatização, o que contrasta significativamente com o estudo de Frey e Osborne que indicava que $47 \%$ dos empregos dos EUA estão em alto risco de serem automatizados. De acordo com Moniz, esta diferença ocorre porque mesmo as profissões dominadas pelo trabalho rotineiro incluem tarefas cujo carácter qualitativo (e.g. tarefas interativas) as mantém como fundamentais nas estruturas de trabalho.

O livro aponta também para a necessidade de enquadrar os principais estudos internacionais no contexto da economia portuguesa, para compreendermos o impacto que o desenvolvimento tecnológico poderá provocar no mercado de trabalho. $\mathrm{O}$ autor indica que não existem estudos científicos que abordem a relação entre robótica e trabalho em Portugal. De facto, os estudos de referência sobre o tema são internacionais, a produção científica nacional é muito limitada e não existem estatísticas disponíveis sobre o número de robôs em Portugal. Apesar disso, António Brandão Moniz consegue examinar com detalhe a evolução da situação desde os anos 80 e o estado atual da robótica no nosso país.

O autor descreve a investigação portuguesa principalmente centrada na academia (e engenharia), com uma relação limitada com as poucas empresas de robótica em Portugal e dependente das linhas de financiamento europeias. O livro indica que o sistema de financiamento à investigação na área em Portugal continua a ser baseado em disciplinas científicas, ao contrário do sistema Europeu. De facto, a União Europeia promove temas de investigação orientados para problemas concretos, estimulando a constituição de equipas de investigação interdisciplinares e obrigando à constituição de painéis de avaliação com peritos de várias disciplinas científicas que avaliam propostas de investigação de reposta à problemática. Neste contexto, a definição das linhas de financiamento europeias poderia talvez ter sido mais explorada na sua relação com os limites impostos à investigação portuguesa pelos grandes consórcios europeus de investigação aplicada e comerciais que definem tais linhas em Bruxelas. Esta orientação permitiria não só compreender melhor a frágil relação entre a academia e as poucas empresas portuguesas de robótica, mas também revelar alguns problemas comuns em outras áreas de investigação aplicada em Portugal.

O livro aborda ainda os recentes desenvolvimentos de sistemas robóticos autónomos (e.g. transporte, segurança), as atuais dificuldades de integração de sensores (visão, velocidade e posicionamento) e de autonomia energética, sublinhando que existem princípios e problemas de carácter ético, legal e social que não se encontram resolvidos. O autor salienta que, em questões associadas ao trabalho e à perceção do ambiente de trabalho, a carga mental e a complexidade da informação a ser tratadas pelos humanos podem representar um limite à difusão e desenvolvimento destes sistemas. 
Em suma, o livro "Robótica e trabalho. O futuro hoje" de António Brandão Moniz é um contributo importante para o debate atual sobre a relação crescente entre tecnologia e trabalho e sobre o impacto da evolução tecnológica no futuro do país. O livro descreve o estado do conhecimento nesta área abordando temas centrais associados à automação e à robótica relacionados com o emprego, a qualificação, a produtividade, a organização do trabalho e a autonomia de sistemas robotizados. O autor indica que muitos dos receios da discussão sobre trabalho e robótica dos anos de 1970 e 1980 permanecem na discussão atual, e que novos medos foram induzidos pela crescente capacidade de inteligência integrada nas máquinas. Apesar de muitos dos limites tecnológicos ainda serem antigos, afirma o autor, novos desenvolvimentos associados a estes artefactos têm vindo a quebrar as barreiras existentes. Assim, António Moniz manifesta a sua preocupação com estas "crises de crescimento" da robótica, e deixa o leitor a pensar nos sofrimentos que poderá causar a chegada desta tecnologia à adolescência.

\section{Notas}

Por decisão pessoal, o autor do texto não escreve segundo as normas do novo acordo ortográfico.

\section{Referências}

Arntz, M., Gregory, T., \& Zierahn, U. (2016). The risk of automation for jobs in OECD countries: A comparative analysis (OECD Social, Employment and Migration Working Papers, $n^{\circ}$. 189). DOI: 10.1787/5jlz9h56dvq7-en

Frey, C., \& Osborne, M. A. (2013). The future of employment: How susceptible are jobs to computerisation?. Technological Forecasting and Social Change, 114(1), 254-80. DOI: 10.1016/j.techfore.2016.08.019

Data de submissão: 02/11/2018 | Data de aceitação: 28/12/2018 